\title{
Processos de criação e procedimentos de criação
}

\author{
Mara Lafourcade Rayel ${ }^{1}$
}

\section{Introdução}

Nosso objetivo com este trabalho é analisar, sob o ponto de vista das ideias de Espinosa sobre o segundo e o terceiro gêneros de conhecimento, as ideias de Cecilia Salles acerca de processos de criação para demonstrar a sua complementaridade. Nosso problema é avaliar em que medida os processos de criação trazem em si movimentos que se alinham ao dos dois modos de conhecimento espinosanos. Nossa hipótese é a de que os aspectos apontados por Salles em suas duas obras, Gesto inacabado (2011) e Redes da criação (2014), podem ser lidos fazendo uso do instrumental espinosano, uma vez que, ao descrever a experiência artística, a autora nos leva a concluir que seu estudo se constitui como ferramenta para desenvolver uma teoria do conhecimento. Nosso método, em um primeiro momento, lança mão de um recurso de apropriação livre das ideias de Salles, acrescentando ainda os fundamentos da mestiçagem cultural preconizados por Amálio Pinheiro especialmente em sua obra América Latina: Barroco, cidade, jornal (2013). Com esse recurso pretendemos dar a ver os procedimentos de criação no exercício da escrita de um texto teórico, de acordo com alguns preceitos expostos por Salles. Em seguida, vamos traçando e aprofundando as análises das obras propriamente ditas, estabelecendo as interseções possíveis e demonstrando gradativamente que o pensamento de Salles e Espinosa pode ser associado de modo a evidenciar sua complementaridade.

\section{Apropriação para aproximar}

Isto ainda não é o artigo. Por ora chamaremos a isto relatório de impressões. Melhor seria dizer relato. Incorporação. Pensávamos em unir as ideias de Cecilia Salles às de Espinosa, mas se impõem, também, as ideias de Amálio Pinheiro - interlocutor frequente de Salles - sobre mestiçagem. Interstícios. Entrelaçamentos. Algo de caldo e de treliça que se move o tempo inteiro (Amálio Pinheiro). Semiose (Cecilia Salles). O momento primeiro. As ideias vindo em jatos. Os afetos aumentando ou diminuindo a potência de existir (Espinosa).

Isto é sobre criar. O que é criar. Como se cria. Criar como um ato de liberdade. Trazer à tona em meio ao caos algo que se relaciona. Relações. Salles fala de relações o tempo inteiro. Espinosa fala de relações o tempo inteiro. Espinosa fala de relações do segundo gênero de conhecimento. Isto é falar de relações que se fazem e se modificam e modificam o tecido do que vemos. Isto é estar no meio de ideias que se entrecruzam e fazem espoucar um mundo inteiro.

Criar um mundo. Criar mundos. Fazer do que sentimos e acumulamos um algo que modifica o modo como vemos. Ignácio. Senise. Klee. Van Gogh ${ }^{2}$. Perseguir a linha que os conduz. Perseguir a linha que eles traçam. E

\footnotetext{
1 Doutora em Comunicação e Semiótica pela Pontifícia Universidade Católica de São Paulo (PUC/SP). Contato: mara.rayel@gmail.com.
} 
não é uma linha, mas um entrelaçamento delas. Um plano pluridimensional de afetos e relações. Algo que se captura ou que se quer capturar. Um mundo a fagulhas que só faz por centelhar.

Pega a mão, traça o desenho que vai se transformar em massa de texto pela página. Traço, traço, traço, cinco linhas que vão ser as linhas mestras de um pensamento seco. Que vai inaugurar um mundo seco.

Os parágrafos de quatro linhas de Brandão ${ }^{3}$. Diagrama traçado de afeto. Aquilo ali é um tecer de uma atmosfera. Algo de um mundo em que não se respira. Coisa toda entrecortada. Visível no desenho, no corpo do texto experimentada.

Alguém pensa ali. Projeto poético. Tendência vaga. E a angústia a abordar, a assombrar com sua falta. Ou com sua pletora de atos que o corpo ainda não tem como acolher. Criar é estar em contato com o mínimo do ser. Com o mínimo do ser imerso no caos de afetos que se apresentam. É experimentar toda a dor daquele momento.

Algo que se cria, que precisa se criar. O corpo do artista. E o que é o artista se não alguém que ousa não recusar afundar? Estar em pleno meio de muitos afetos. De muitas afecções.

Digo, porém, que, em geral, quanto mais um corpo é capaz, em comparação com outros, de agir simultaneamente sobre um número maior de coisas, tanto mais sua mente é capaz, em comparação com outras, de perceber, simultaneamente, um número maior de coisas. E quanto mais as ações de um corpo dependem apenas dele próprio, e quanto menos outros corpos cooperam com ele no agir, tanto mais sua mente é capaz de compreender distintamente. ${ }^{4}$

Incorporar várias línguas que se apresentam. Em meio a uma floresta de imagens. Em meio a uma floresta de ideias. Em meio a uma floresta de afetos. Na iminência constante de perdê-las. Anotar, desenhar, fotografar. Rabiscar. Confiscar os momentos que parecem cheios de realidades e depois se arriscar a exprimi-los. Difícil tarefa. A de exprimir esses momentos tão plenos e caudalosos. Difícil tarefa a de reunir momentos numa linha inconstante em que a língua, o gesto parecem faltar. $\mathrm{O}$ artista exercita constantemente a arte de poder se deixar afetar o máximo possível, como quer Espinosa.

Projeto poético. Projeto de vida. $\mathrm{O}$ artista se autoconhece nos momentos em que quer reunir. $\mathrm{O}$ artista se autoconhece nos momentos em que se debate. Nada está definido. Tudo pode se perder. É por isso que é preciso anotar, anotar, anotar. Desenhar, traçar. Tentar capturar o "instante-já que de tão fugidio não é

\footnotetext{
${ }^{2}$ Artistas citados por Salles nas obras em análise: Ignácio [de Loyola Brandão], [Daniel] Senise, [Paul] Klee, [Vincent] Van Gogh.

${ }^{3}$ Ignácio de Loyola Brandão, escritor brasileiro citado por Salles nas obras em análise.

${ }^{4}$ SPINOZA, B. de. Ética. Tradução: Tomaz Tadeu. Belo Horizonte: Autêntica, 2007. A citação no texto refere-se à parte II, escólio da proposição 13, que, na edição aqui mencionada, encontra-se na p. 99. Neste trabalho, em nossas menções ao filósofo, adotamos a grafia "Espinosa", não obstante encontrarmos variadas formas, como Spinoza (como a própria edição da Autêntica) e Espinoza, conforme se pode constatar nas Referências bibliográficas. Como se trata de obra fundamental, que recebeu as mais variadas edições e traduções, julgamos pertinente, além da remissão direta à página da edição por nós utilizada (SPINOZA, 2007), fazer menção à parte a que nos referimos (I, II, III, IV ou V) e às subdivisões específicas, por meio de abreviações (exemplos: def. para definição, ax. para axioma, prop. para proposição, dem. para demonstração, corol. para corolário, esc. para escólio etc.). Isso possibilitará aos leitores a localização do trecho independentemente da edição que tiverem em mãos.
} 
mais" ${ }^{5}$. Algo nele quer relatar a experiência de ser entre as coisas como coisa. Mais uma coisa a pulsar. Antes o que era. Não havia um antes. Não há um depois.

Sem início e sem fim, o processo se dá inteiro pela procura do avesso. E o que é o avesso se não o expor para o outro o cúmulo de relações que se engendram? Escrever, desenhar, pintar, fotografar, esculpir, gravar, filmar é tudo coisa da mesma laia. Um avesso que quer sair. Um avesso que é limiar. Entre um dentro e um fora.

Nunca, pois, um animal, uma coisa, é separável de suas relações com o mundo: o interior é somente um exterior selecionado; o exterior, um interior projetado; a velocidade ou a lentidão dos metabolismos, das percepções, ações e reações entrelaçam-se para constituir tal indivíduo no mundo. ${ }^{6}$

Estamos imersos em nossas sensações e percepções. Estamos imersos em nossos sentimentos. Estamos, às vezes, que o corpo é só memória. O mundo se reúne em mim. "Serei eu Deus?" (Paul Klee). Como conseguir ficar em paz com isso que se impõe aqui? Nos meus dias. No meu modo de sentir. Isso que não ouso dizer que não seja só esse nome: criar. Fazer a diferença que vejo. $\mathrm{O}$ artista não quer representar o que vê, mas mostrar o que não está visível (Paul Klee) ${ }^{8}$. Algo. Que de tão repetido só pode ser alguma coisa que não se pode nomear.

Imaginação? É pouco (para Espinosa é muito pouco). Pensamento. Ação em um mundo em que somos a maior parte do tempo padecentes, passivos (Espinosa). Mas o que vem por aqui? A vida que quer vir. A vida que quer vida e que por isso vibra num bruxuleio da realidade. Muitas miríades de coisas. Falas. Culturas. Modos de viver. Modos de cantar. A vida que se ergue da capacidade de poder participar. Matéria mestiça. Muitos saberes. Muitos sentidos da paisagem e do outro que me afeta. Mestiçagem. Modo de sentir. Modo de viver. O artista mescla o mundo e inaugura novas formas de viver. Inaugura realidades. Aliado a realidades e imaginações. Mas mais a realidades.

É preciso falar das noções comuns de que fala Espinosa nas partes II e IV da Ética. Aquelas que existem entre mim e o que me afeta. Noções comuns que me levam a compreender um ritmo nessa senda que se abre porque não posso viver sem participar. $\mathrm{O}$ artista é aquele que participa e, como parte, toma parte num mundo imenso que ele desconhece e que inclui ele mesmo. Quando em meio a um projeto poético/projeto de vida encontra as noções comuns, então ele pode contar. Daniel Senise e seus pregos e bumerangues. Inácio de Loyola Brandão e suas bicicletas mortas. Paul Klee e sua cor. Pregos a pintar o movimento de bumerangues. Bicicletas que morrem a construir guarda-chuvas. Cor que ainda não era minha. São todas imagens. Mas algo que passa pelo corpo e se compõe com ele. E há o desejo. Tendência vaga. Somos afetados pelo meio. Mas captamos do meio só aquilo que o corpo pode sentir.

\footnotetext{
${ }^{5}$ Lispector, C. Água viva. Rio de Janeiro: Rocco, 1998, p. 9.

${ }^{6}$ Deleuze, G. Espinosa: filosofia prática. Tradução: Daniel Lins e Fabien Pascal Lins. São Paulo: Escuta, 2002, p. 130.

${ }^{7}$ KLEE, P. Diários. São Paulo: Martins Fontes, 1990, p 216.

${ }^{8}$ KLEE, P. Confissão criadora. In: Sobre a Arte Moderna e Outros Ensaios. Tradução: Pedro Süssekind. Rio de Janeiro: Jorge Zahar Editor, 2001, p. 46.
} 


\section{O sentido de sentir}

E é aqui que começa o artigo. O que o corpo pode sentir? O que o corpo pode? Espinosa não separa o corpo da mente: "A ordem e a conexão das ideias é o mesmo que a ordem e a conexão das coisas"". Amálio Pinheiro diz do "miúdo incluso que varia"10. Todo esse franjar de coisas. Estamos imersos e por isso nosso conhecimento é mutilado e confuso ${ }^{11}$. Para conhecer, no sentido espinosano, é preciso fazer um esforço: o primeiro esforço da razão é selecionar as alegrias ${ }^{12}$. Então, nessa febre que é conhecer, estaremos o tempo inteiro procurando fazer operações físico-químicas ${ }^{13}$. Procurando combinar elementos. Como aponta Salles, "O meio de expressão já está inserido no desejo" ${ }^{14}$. Nessa volta que se dá vemos a potência, que é igual a desejo, fazer suas conjeturas. Modo de conhecer. Afetados imensamente, vemos que o artista constrói a partir de si.

Criar livremente não significa fazer qualquer coisa, a qualquer momento, em quaisquer circunstâncias e de qualquer maneira. As delimitações são como as margens de um rio pelo qual o indivíduo se aventura no desconhecido. Vemos o ser livre como uma condição seletiva, sempre vinculada a uma intencionalidade presente, embora talvez inconsciente, e a valores individuais e sociais de um tempo. ${ }^{15}$

Somos formados por indivíduos que por sua vez são constituídos por corpos em uma relação complexa. E essa relação complexa se dará de maneira indefinida ao longo da duração ${ }^{16}$. Somos afetados constantemente pelo meio. Determinados de fora. Isso se conecta à citação precedente de Salles, uma vez que, "como as margens de um rio", o exterior sempre nos afeta.

E o que isso quer dizer? Que a liberdade não está dada. A liberdade é uma conquista. Que se dá se podemos primeiro selecionar os afetos de alegria e depois efetuar relações. Nesse jogo, nessa dança o que importa é entender as causas das coisas. As causas dos próprios afetos. Na construção de si, o artista estabelece relações e com isso inaugura novas formas de configurar. Teria o artista alcançado a liberdade? Não apressemos as coisas.

O processo criador é um percurso com "um objetivo a atingir, um mistério a penetrar", de acordo com Picasso (1985). A intenção do artista é pôr obras no mundo. Ele é, nessa perspectiva, portador de uma necessidade de conhecer algo, que não deixa de ser um conhecimento de si mesmo, como veremos, cujo alcance está na consonância do coração com o

\footnotetext{
${ }^{9}$ SPINOZA, B. de. Op. cit., II, prop. 7, p. 87.

${ }^{10}$ Pinheiro, A. América Latina: Barroco, cidade, jornal. São Paulo: Intermeios, 2013, p. 15.

${ }^{11}$ SPINOZA, B. de. Op. cit., II, prop. 40, esc. 2, p. 133.

${ }^{12}$ Deleuze, G. Op. cit., p. 123.

${ }^{13}$ Ibidem, p. 120.

${ }^{14}$ SALLES, C. Op. cit., p. 43.

${ }^{15}$ Ibidem, p. 69, fazendo menção a OSTROWER, F. Criatividade e processos de criação. Petrópolis: Vozes, 1978, p. 69.

${ }^{16}$ Essas ideias são desenvolvidas por Espinosa, na Ética (2007), na parte II, ao longo dos lemas, axiomas, escólios, definição e postulados que se seguem à proposição 13.
} 
intelecto. Desejo que nunca é completamente satisfeito e que, assim, se renova na criação de cada obra. $^{17}$

Imersos como partes constituídas por partes, o conhecimento que temos de nós mesmos e do mundo só se dá por meio das afecções sofridas. Somos, como dissemos, determinados de fora o tempo inteiro e só podemos nos conhecer ao padecermos. Nesse enlace em que estamos inexoravelmente com as coisas sofremos variação contínua em nossa potência de existir. Quando algo nos afeta e convém ao nosso corpo e à nossa mente, nossa potência aumenta: sofremos uma paixão alegre ou um afeto de alegria. Quando algo não nos convém e diminui a nossa potência de existir, sofremos uma paixão triste ou um afeto de tristeza. Pensamos, nesse processo, conhecer as causas de nossas afecções, mas só temos acesso aos efeitos, às impressões deixadas pelas coisas em nós. Assim, Espinosa diz que imaginamos e que as ideias que temos sobre nós e as coisas são ideias inadequadas, pois não conhecemos as causas implicadas naquela afecção. Resulta disso que quando somos afetados o que conhecemos é apenas a impressão que o corpo exterior deixou em nosso corpo, ou seja, não conhecemos nada desse corpo exterior. Sendo assim, não conhecemos adequadamente nem a nós mesmos e não somos livres porque ignoramos. Como sair disso? Espinosa diz que é preciso fazer um esforço para pensar. O que nos leva a dizer, também, que o modo de sair do primeiro gênero de conhecimento envolve a ação, envolve criar, de acordo com Salles, "na consonância do coração com o intelecto".

Quando a mente está

interiormente determinada, por considerar muitas coisas ao mesmo tempo, a compreender suas concordâncias, diferenças e oposições. Sempre, com efeito, que está, de uma maneira ou outra, interiormente arranjada, a mente considera as coisas clara e distintamente [... $]^{18}$.

O processo é de conhecimento de si enquanto se é afetado pelo mundo. Conhecer os seus próprios afetos ${ }^{19}$. Em suma, em suas pesquisas o artista exercita o conhecimento de si e de seus próprios afetos. O que ele faz? Ele se põe em causa. Ele entra em contato com ideias, fazeres, experimentações.

O acompanhamento de processos de criação nos mostra que a efervescência cultural incita o artista. O profundo comprometimento com as obras em construção o põe em condições propícias para encontros nessa turbulência cultural. Os documentos registram muitos momentos de intensidade, nos quais relações ficam claras: ele tudo olha, recolhe o que possa parecer de interesse, acolhe e rejeita, faz montagens, organiza, ideias se associam, formas alternativas proliferam e pesquisas integram a obra em construção. Enfim, um turbilhão de possibilidades interativas. $^{20}$

\footnotetext{
${ }^{17}$ SALlES, C. Op. cit., p. 38.

18 SPINOZA, B. de. Op. cit., II, esc. à prop. 29, p. 123.

${ }^{19}$ Ibidem, V, esc. à prop. 4, p. 373.

${ }^{20}$ SALLES, C. Redes da criação: construção da obra de arte. 2. ed. São Paulo: Horizonte, 2014, p. 40.
} 
Em outras palavras, como parece deixar claro Salles na citação acima, o artista é aquele que de certa forma aceita ser determinado pelo turbilhão. Não podemos definir ao certo o que o faz aberto às interações. Como dissemos, ele está imerso no mundo e sofre afecções o tempo inteiro. Mas ele guarda uma disposição interna de investigar aquilo que o afeta. Ele mede, configura, confisca, esboça num movimento de busca de algo que ele pode até não saber conscientemente o que é, mas que sem dúvida envolve uma autoexperimentação. Com esse procedimento ele se torna mais apto a ser afetado simultaneamente por um número maior de coisas. E, como vimos, quanto mais apto a ser afetado simultaneamente por um número maior de coisas, mais conhecimento de si, de seus próprios afetos ele vai alcançar. "Quem compreende clara e distintamente a si próprio e os seus afetos, alegra-se, com uma alegria que vem acompanhada da ideia de Deus" ${ }^{21}$.

Já vimos que a alegria aumenta nossa potência de existir e, portanto, colabora para que cheguemos a formar ideias adequadas.

Não se pode, no entanto, limitar o olhar poético à experiência visual, mas devemos pensá-lo como o instante de estabelecimento de relações por meio da harmonia dos sentidos. A sensibilidade apreende essas imagens mentais que responderam a um estímulo e - assim - une mundos experienciados por diferentes meios. ${ }^{22}$

Repetimos com Salles: "devemos pensá-lo como o instante de estabelecimento de relações por meio da harmonia dos sentidos". O que nos leva de volta às noções comuns. As ideias adequadas nascem do conhecimento das noções comuns que há entre mim e os corpos que me afetam. Entendo, pois, as relações entre esses elementos. Sou capaz de relacionar esses elementos e, com isso, de arranjar-me de modo a apresentar ao mundo essa relação. Mas essa relação eu estabeleço por meio de mim. Uma ideia adequada é uma ideia expressiva, "é a ideia que exprime sua própria causa e que se explica pela nossa própria potência" ${ }^{23}$. No momento mesmo em que tenho uma ideia adequada torno-me ativo, isto é, aproprio-me de minha potência, ajo em mim e no mundo. Ao estabelecer relações, encontro um modo diferenciante de agir que não está mais sujeito passivamente às afecções, ao que é exterior a mim. Sou um corpo capaz de agir, isto é, sou uma mente que é capaz de pensar.

Capítulo 2. Os desejos que se seguem de nossa natureza, de maneira tal que podem ser compreendidos exclusivamente por meio dela, são os que estão relacionados à mente, à medida que esta é concebida como consistindo de ideias adequadas. Quanto aos outros desejos não estão relacionados à mente senão à medida que esta concebe inadequadamente as coisas. A força e a expansão desses desejos devem ser definidas não pela potência humana, mas pela potência das coisas que estão fora de nós. Por isso, os primeiros desejos são, apropriadamente, chamados de ações, enquanto os segundos são chamados de paixões; pois os primeiros indicam

\footnotetext{
${ }^{21}$ SpINOZA, B. de. Op. cit., V, dem. à prop. 15, p. 383.

22 SALLES, C. Op. cit., 2011, p. 97.

23 Deleuze, G. Espinosa e o problema da expressão. Tradução: GT Deleuze. Coordenação: Luiz B. L. Orlandi. São Paulo: Editora 34, 2017, p. 166.
} 
sempre a nossa potência, enquanto os segundos indicam, ao contrário, a nossa impotência e um conhecimento mutilado. ${ }^{24}$

Ações porque indicam a nossa potência. Ações que implicam a concatenação de ideias adequadas segundo a ordem própria do intelecto ${ }^{25}$. Ações que implicam o estabelecimento de relações por meio daquelas relações que já conheço. Eu me aproprio de minha potência e sou capaz de agir. Sou capaz de me modificar e, ao modificarme, sou capaz de estabelecer novos modos de relação que estão em consonância com a natureza, posto que a natureza cria o tempo inteiro. Isso nos leva a concluir que o ato de criação está vinculado às ideias adequadas e à apropriação da nossa potência. Na medida em que ajo no mundo, crio, invento novos modos de ser. Crio novos modos de sentir.

O artista cria blocos de perceptos e de afectos, mas a única lei da criação é que o composto deve ficar de pé sozinho. [...] Manter-se de pé sozinho não é ter um alto e um baixo, não é ser reto (pois mesmo as casas são bêbadas e tortas), é somente o ato pelo qual o composto de sensações criado se conserva em si mesmo. ${ }^{26}$

Isso é o que faz Bill Viola em uma experiência descrita por Cecilia Salles em seu Redes da criaçãa $^{27}$. O artista cria um bloco de perceptos e afectos a partir de uma experiência vivida que o impressionou. Ele criou um modo de afetar seu público. Ele criou uma nova relação a partir da relação que ele mesmo estabeleceu. Sua percepção visual inteiramente imersa na experiência vivida estabeleceu uma nova forma de sentir, criada a partir de sua instalação de câmera de vídeo e gota d'água. Ele não reproduziu o que viu. Ele não representou o que viu. Ele construiu uma máquina de ampliar a visão. Uma máquina de sensação.

Isso é o que se cria quando se cria.

\section{Conhecimento das relações}

"A arte não reproduz o visível, mas torna visível"28. Repetimos e seguiremos repetindo essa frase de Klee. O tornado visível é o mundo das relações a que de um modo ou de outro o artista acede. Mais que isso, é, como nos diz Espinosa na parte V da Ética, o mundo das essências singulares (terceiro gênero de conhecimento). Potências que convêm umas com as outras porque são a própria expressão da potência de Deus ou da Natureza. Para Espinosa, nada na natureza é passível de críticas ou de deplorações. Tudo se combina de um modo ou de outro, efetuando configurações e desconfigurações que resultam em outras configurações.

\footnotetext{
${ }^{24}$ SPINOZA, B. de. Op. cit., IV, apêndice, p. 351.

${ }^{25}$ Ibidem, V, prop. 10, dem., p. 379.

${ }^{26}$ Deleuze, G.; Guattari, F. O que é a Filosofia? Tradução: Bento Prado Jr.; Alberto Alonso Muñoz. São Paulo: Editora 34, 2000, p. 214.

27 SALLES, C. Op. cit., 2014, p. 128-130.

${ }^{28}$ KLEE, P. Op. cit., 2001, p. 46.
} 
O artista, quando de posse de sua potência, é capaz de engendrar esse mundo e a dinâmica que há nele. Uma sinfonia. Guernica. A Noite estrelada de Van Gogh. O filme 8 e 1/2 de Fellini. Villa Lobos. Uma paisagem de Burle Marx. Um parangolé de Oiticica. Capturas do engruvinhamento do "plano de imanência" ${ }^{29}$.

Não é de ficção que se trata. Mas dos afetos que estão dados naquele instante precário e que o artista pode captar. Algo ali já existe. Não está latente. Está vivo e agindo e o que o artista faz é trazer à tona de modo que as pessoas possam sentir. Uma filigrana de mundos que subsistem, insistem por momentos efêmeros, é bem verdade.

Esse envolvimento transformador é responsável pelo estabelecimento de elos. O artista está ligado e precisa da realidade externa ao mundo ficcional, no sentido que se alimenta dela. $\mathrm{O}$ ato criador estabelece novas conexões entre os elementos apreendidos e a realidade em construção, desatando-os, de certa maneira, de seus contextos. ${ }^{30}$

Perguntamos se esse "desatar de contextos", do qual nos fala Salles, não seria propriamente atar a contextos intuídos (terceiro gênero de conhecimento) que não estão evidentes no modo precário como enxergamos (partes que somos), mas que se tornam evidentes ao termos ideias adequadas, ideias que expressam sua própria causa.

O processo de criatividade é, indiscutivelmente, semelhante ao da evolução, especialmente como Peirce descreveu esse processo biológico e cultural de geração de novas possibilidades. É um processo no qual estão em jogo: variação pelo acaso, modelos herdados de esforços continuados e eventos cataclísmicos impondo imensas demandas sobre criaturas frágeis. É, sobretudo, um processo no qual a seleção é geradora de possibilidades. Isto é, a seleção não é apenas ou principalmente um processo de eliminação. A seleção é, em alguns aspectos cruciais, geradora, abrindo ou expandindo um campo de possibilidades, ao invés de limitar ou destruir esses campos. $^{31}$

Diríamos que não se trata de possibilidades apenas, mas de afetos que já estão em jogo ali, naquela cena. E aquela cena é o real, mais do que a realidade; o artista toca o real, quando acede às ideias adequadas e às relações, na sua sanha de conhecer.

Sabemos o quão pouco ortodoxa pode ser considerada essa afirmação. Mas estamos trabalhando já num mundo sem sujeito e objeto. Num mundo sem síntese. Sem dialética. Num mundo que incorpora o inteiramente outro e toca nas relações e toca nas essências elas mesmas.

Quando Espinosa descreve os conhecimentos de segundo e terceiro gêneros, ele está falando já de modos de conhecimento que prescindem dos signos. O conhecimento que se dá por meio dos signos é o que ele caracteriza de primeiro gênero de conhecimento. O segundo gênero é o que se dá por meio das noções comuns e o terceiro,

29 DeleUZe, G. Op. cit., 2002, p. 133.

30 SALLES, C. Op. cit., 2011, p. 100.

31 Colapietro, V. Os locais da criatividade: sujeitos fissurados, práticas entrelaçadas. Tradução: Cecilia Salles. In: PINHEIRO, A.; SAlles, C. A. (Org.). Jornalismo expandido: práticas, sujeitos e relatos entrelaçados. São Paulo: Intermeios/PUC-SP, 2016, p. 60. 
chamado de ciência intuitiva, é o que se dá pela apreensão das essências formais de certos atributos de Deus e que leva ao conhecimento das essências das coisas ${ }^{32}$.

Diante disso, temos perfeita noção das implicações que pode haver em afirmar que o artista é aquele que atingiu de alguma maneira o segundo e o terceiro gêneros de conhecimento. Quer dizer então que o artista é aquele que conquistou a liberdade? Não pretendemos levar adiante essa pressuposição. Defendemos, contudo, a ideia de que o artista, com suas experimentações - que incluem, como já afirmamos, com Salles, experimentações de si -, adota procedimentos desses gêneros de conhecimento. No movimento de criar estão implicadas ações, e ações, como já demonstramos, segundo Espinosa, "indicam sempre a nossa potência". A disposição do artista em sentir, em ser afetado, em suma, o coloca num movimento que pode levá-lo a ter ideias adequadas ou ideias expressivas, como quer Deleuze.

Não se pode desvincular o tempo das criações de obras como o tempo de autocriação. O grande projeto do artista, imerso em sua cultura e tradição, é vinculado a suas necessidades, paixões e desejos. Trata-se de um conjunto de comandos éticos e estéticos, ligados a tempos e espaços, e com fortes marcas pessoais. O percurso criador, ao gerar uma compreensão maior do projeto, leva o artista a um conhecimento de si mesmo. Daí o percurso criador ser para ele, também, um processo de autoconhecimento e, consequentemente, autocriação, no sentido de que ele não sai de um processo do mesmo modo que começou: a compreensão de suas buscas estéticas envolve autoconhecimento. ${ }^{33}$

Como Salles deixa evidente acima, tudo se trata, pois, de modos de viver. Ética é igual a maneiras de viver. E é disso que fala Espinosa o tempo inteiro em sua obra. Há uma força que coloca o artista no encalço de um algo. Tendência vaga (Salles). Mas de um algo capaz de movê-lo por entre seus próprios afetos ou apreensões. Nada falta ao artista. Nada falta ao desejo. Mas o movimento da vida, o devir de si mesmo e das coisas, o leva a querer entrar em contato com esse algo, que parece vago e, que, contudo, o define. Tendemos ao mundo das ideias adequadas, das ideias que expressam sua própria causa. É esse mundo que move o artista. Que o faz mover-se em direção a um conhecimento de si.

Entrelaçados. Estamos entrelaçados como forças que se engendram entre velocidades e lentidões, movimento e repouso. E entre afetos. $\mathrm{O}$ artista, com sua sensibilidade não escolhida, se vê em meio a esse mundo de coisas. $\mathrm{O}$ artista, como todos os mortais, é determinado de fora por seus afetos (primeiro gênero de conhecimento). E esses afetos o movem a expressar o que vai por ali. $\mathrm{O}$ artista não escolhe seu modo de estar no mundo. Mas não recusa, ou não pode recusar, sua sensibilidade (embora sofra com ela, por incontáveis vezes). E é por não recusar o que sente que muitas vezes encontra um modo novo de estar no mundo. E, com isso, um modo novo de ver o mundo. Um modo que vê o mundo já sem o limite das percepções determinadas de fora. Um modo novo das percepções que se conhecem como causa de seus próprios afetos:

Somente quando, sob o esforço da Razão, as percepções ou ideias se tornam adequadas, e os afetos ativos, somente quando nos tornamos nós mesmos causa dos nossos próprios afetos e

\footnotetext{
32 SpINOZA, B. de. Op. cit., II, prop. 40, esc. 2, p. 135.

${ }^{33}$ SALLES, C. Op. cit., 2014, p. 65.
} 
senhores das nossas percepções adequadas, é então que o nosso corpo tem acesso à potência de agir e o nosso espírito à potência de compreender, que é a sua maneira de agir. ${ }^{34}$

Esse é o vislumbre de um mundo de afetos ativos. De um mundo que prescinde dos signos. Que se move entre eles, sem dúvida, mas que está aquém ou além dos signos. Um mundo de intensidades. De forças ativas que entram em consonância com o respirar da matéria. Com o ritmo das coisas. Com o entrechoque dos átomos, das moléculas.

Viver nesse entremundo não é para muitos. É necessário aceitar o que lhe vem. E aprender, no cadenciar dos dias, a encontrar o seu próprio ritmo, a sua própria respiração. O artista, por vezes, habita esse mundo. Mesmo que à sua revelia. Afinal, somos determinados de fora e precisamos aprender a nos tornar causa de nossos próprios afetos.

A aceleração dos dispositivos tradutórios inscritos nos mecanismos produtivos das culturas plurais intensifica reticularmente o pendor para a incorporação material do alheio. Tal incorporação só pode ser percebida, na maior parte das vezes, nas junturas ou dobradiças em que as partículas são transferidas intersticialmente de umas linguagens para outras, onde se desenha esse entre mestiço de formas em devir. O que aí toma corpo são pequenas diferenciações transversas de tom ou ritmo e não oposições entre marcadas diferenças. ${ }^{35}$

Esse entre mestiço de que fala Amálio Pinheiro descreve bem o mundo dos afetos e das noções comuns e das essências formais dos atributos de Deus. Descreve na realidade isso com que estamos de um modo ou de outro em contato e que não percebemos, ou recusamos. Isso, esse mundo estranho que insiste em nos visitar e é simplesmente o real do qual falamos. O real, mundo da substância ou natureza ou Deus. É por isso que aludimos no começo deste texto ao mundo da mestiçagem. Porque de alguma forma ele entranha essa "tensão relacional que se mantém como ligação móvel em suspensão" ${ }^{36}$. E enseja o mundo dentro do qual o artista, como aponta Salles e segundo o que vimos em Espinosa, se move irrevogavelmente e dele traz matérias novas, novas relações, instâncias novas que nos fazem por fim sentir sem refugar.

\section{Conclusão}

O que fizemos aqui foi um enlace das ideias de Salles com as ideias de Espinosa. Mais do que associálas, colocamo-las em circunstância de ampliação. Baseando-nos nos processos criativos descritos por Cecilia Salles, introduzimos as proposições do filósofo acerca do que sejam o segundo e o terceiro gêneros de conhecimento. Ao nos valermos das pesquisas de Salles, nos colocamos em defesa de que os procedimentos de segundo e terceiro gêneros de conhecimento podem ser associados aos processos de criação artística. Ou, antes, que os processos de criação artística de alguma forma engendram em si os procedimentos de segundo e terceiro gêneros de conhecimento. Com isso, o que esperamos ter deixado explicitado é que o fazer artístico é

\footnotetext{
${ }^{34}$ DeleuZe, G. Op. cit., 2002, p. 109.

${ }^{35}$ Pinheiro, A. Op. cit., 2013, p. 18.

${ }^{36}$ Ibidem, p. 94.
} 
uma apropriação de conhecimento e, como tal, pode inaugurar em suas obras maneiras novas de enxergar e de sentir o mundo e, sem dúvida, maneiras novas de nos sentirmos.

\section{Referências bibliográficas}

COlAPIETRO, V. Os locais da criatividade: sujeitos fissurados, práticas entrelaçadas. Tradução: Cecilia Salles. In: PinheIro, A.; SAlles, C. A. (Org.). Jornalismo expandido: práticas, sujeitos e relatos entrelaçados. São Paulo: Intermeios/PUC-SP, 2016.

Deleuze, G. En medio de Spinoza. Tradução: Equipo Editorial Cactus. 2. ed. Buenos Aires: Cactus, 2013.

DeleuZe, G. Espinosa: filosofia prática. Tradução: Daniel Lins e Fabien Pascal Lins. São Paulo: Escuta, 2002.

Deleuze, G. Espinoza e os signos. Tradução: Abílio Ferreira. Porto: Rés-Editora, s/d.

DeleuZE, G. Espinosa e o problema da expressão. Tradução: GT Deleuze. Coordenação: Luiz B. L. Orlandi. São Paulo: Editora 34, 2017.

Deleuze, G. Ideia e afeto em Spinoza. Aula de 24 jan. 1978. Disponível em: http://www.webdeleuze.com/php/texte.php?cle=194\&groupe=Spinoza\&langue=5. Acesso em: 15 nov. 2020.

DeleuZe, G. Lógica do sentido. Tradução: Luiz R. Salinas Fortes. São Paulo: Perspectiva, 2007.

DeleuZe, G. Spinoza et le problème de l'expression. Paris: Les Éditions de Minuit, 1968, 2010.

DeleuZe, G.; GuAtTARI, F. Mil platôs - capitalismo e esquizofrenia. Tradução: Ana Lúcia de Oliveira (coord.). São Paulo: Editora 34, 1995 [v. 1 e 2], 1996 [v. 3], 1997 [v. 4 e 5].

DeleuZe, G.; GuATtARI, F. O anti-Édipo: capitalismo e esquizofrenia. Tradução: Luiz B. L. Orlandi. São Paulo: Editora 34, 2010.

Deleuze, G.; Guattari, F. O que é a Filosofia? Tradução: Bento Prado Jr.; Alberto Alonso Muñoz. São Paulo: Editora 34, 2000.

KLEE, P. Confissão criadora. In: Sobre a Arte Moderna e Outros Ensaios. Tradução: Pedro Süssekind. Rio de Janeiro: Jorge Zahar Editor, 2001. [Edição digital: abril 2014, s/n.]

KLEE, P. Diários. São Paulo: Martins Fontes, 1990, p 216.

LISPECTOR, C. Água viva. Rio de Janeiro: Rocco, 1998.

Pinheiro, A. América Latina: Barroco, cidade, jornal. São Paulo: Intermeios, 2013.

PINHeIRO, A.; SAlles, C. A. (Org.). Jornalismo expandido: práticas, sujeitos e relatos entrelaçados. São Paulo: Intermeios/PUC-SP, 2016.

SALLES, C. Gesto inacabado. 5. ed. revista e ampliada. São Paulo: Intermeios, 2011.

SALLES, C. Redes da criação: construção da obra de arte. 2. ed. São Paulo: Horizonte, 2014.

SPINOZA, B. de. Ética. Tradução: Tomaz Tadeu. Belo Horizonte: Autêntica, 2007.

Recebido em: 14 de dezembro de 2020 Aceito em: 10 de junho de 2021 